\title{
Nanostructural hierarchy increases the strength of aluminium alloys
}

\author{
Peter V. Liddicoat' ${ }^{1}$ Xiao-Zhou Liao², Yonghao Zhao ${ }^{3}$, Yuntian Zhu4, Maxim Y. Murashkin ${ }^{5}$, Enrique J. Lavernia ${ }^{3}$, \\ Ruslan Z. Valiev ${ }^{5} \&$ Simon P. Ringer ${ }^{1}$
}

Increasing the strength of metallic alloys while maintaining formability is an interesting challenge for enabling new generations of lightweight structures and technologies. In this paper, we engineer aluminium alloys to contain a hierarchy of nanostructures and possess mechanical properties that expand known performance boundaries-an aerospace-grade 7075 alloy exhibits a yield strength and uniform elongation approaching $1 \mathrm{GPa}$ and $5 \%$, respectively. The nanostructural architecture was observed using novel high-resolution microscopy techniques and comprises a solid solution, free of precipitation, featuring (i) a high density of dislocations, (ii) subnanometre intragranular solute clusters, (iii) two geometries of nanometre-scale intergranular solute structures and (iv) grain sizes tens of nanometres in diameter. Our results demonstrate that this novel architecture offers a design pathway towards a new generation of super-strong materials with new regimes of property-performance space.

\footnotetext{
${ }^{1}$ Australian Centre for Microscopy and Microanalysis and ARC Centre of Excellence for Design in Light Metals, The University of Sydney, Sydney, New South Wales 2006, Australia. ${ }^{2}$ School of Aerospace, Mechanical and Mechatronic Engineering, The University of Sydney, Sydney, New South Wales 2006, Australia. ${ }^{3}$ Department of Chemical Engineering \& Materials Science, University of California, Davis, California 95616, USA. ${ }^{4}$ Department of Materials Science and Engineering, North Carolina State University, Raleigh, North Carolina 27695, USA. ${ }^{5}$ Institute of Physics of Advanced Materials, Ufa State Aviation Technical University, 12K. Marx Street, Ufa 450000, Russia. Correspondence and requests for materials should be addressed to S.P.R. (email: simon.ringer@sydney.edu.au).
} 
$\mathrm{N}$ early 30 years passed between the discovery of the age-hardening effect by Alfred Wilm in 1906 and the X-ray scattering observations that established the link between this effect and the alloy microstructure ${ }^{1-3}$. It was yet another 20 years before more sensitive X-ray techniques and transmission electron microscopy (TEM) revealed more detailed microstructural origins and correlated age hardening to clusters of solute atoms and precipitate particles ${ }^{4-5}$. In the decades to follow, optimization of the type, size and dispersion of these microstructural features has produced sophisticated alloys now relied upon in many technologies ${ }^{6}$. Such a discovery into structure-to-property origins is a good example of how advances in characterization techniques and instrumentation can enable breakthroughs in materials science and engineering.

Age-hardening effects are now widely used in modern aerospace, automotive and construction materials. In age-hardened aluminium (Al) alloys, relatively high yield strengths, $\geq 0.5 \mathrm{GPa}$, are achieved from thermomechanical treatments that generate precipitation-strengthened microstructures. Significantly, these microstructures retain reasonable ( $>5 \%$ ) levels of uniform elongation in accordance with requirements for structural engineering applications. A survey of property-performance space for a wide range of metallic $\mathrm{Al}$ alloys indicates that values of yield strength of $\sim 0.7 \mathrm{GPa}$ represent the upper strength limit for precipitation-strengthened wrought $\mathrm{Al}$ alloys ${ }^{6-9}$

Severe plastic deformation (SPD) techniques emerged in 1991 as a novel processing strategy to effect grain refinement strengthening with potential for significant property enhancements ${ }^{10-11}$. In the 18 years leading up to the present, SPD alloys have attracted substantial interest, both for fundamental research and technological development ${ }^{8-9,11-18}$. It is now possible, through a variety of SPD techniques, to produce essentially homogenous microstructures exhibiting nanoscale grain refinement, provided select processing pathways are chosen and sufficiently high strain is imparted ${ }^{14,19-20}$. As seen in Figure 1a, Al alloys produced by SPD have recently exhibited tensile yield strengths as high as $\sim 0.75 \mathrm{GPa}$ and elongations up to $\sim 10 \%^{8-9}$. Such SPD alloys are typically strengthened by refined grain dimensions, as well as by the propensity for high dislocation accumulation and by precipitate particles.

There remains an unsatisfactory fit between theory-based structure-property relationships in SPD metals. For example, the veracity of Hall-Petch-type relationships as the grain size reduces below $100 \mathrm{~nm}$ is problematic ${ }^{21-23}$. Anomalies in grain coarsening phenomena have been widely reported, and there is much uncertainty about the precise deformation modes ${ }^{24-26}$. This suggests strongly that new experimentally derived insights into the nanostructure are needed to comprehensively describe the structures within these unusual materials and their influences on properties. Here, it must be noted that electron microscopy and microanalysis of such nanoscale grains is particularly challenging. Images from the thinnest foils in TEM contain convolutions in contrast and spectroscopic information, as most of the grains under study are significantly smaller than the foil thickness. High-resolution scanning electron microscopy can usually be used to image the nanocrystalline grain structure. However, quantitative information on grain misorientation using electron backscattered diffraction is not usually possible in cases in which the average grain size is below $150 \mathrm{~nm}$, and this technique is not presently amenable to quantitative chemical mapping with nanoscale $(<5 \mathrm{~nm})$ spatial resolution. As such, it is well recognized that there is a paucity of detailed characterization of nanostructured alloys.

It is the focus of present research to extend the strength of commercially valuable alloys without sacrificing ductility by engineering nanoscalemicrostructuresornanostructures. If conventionalthermomechanical processing of age-hardenable $\mathrm{Al}$ alloys results in a material dominated by dispersions of microscale, solute-rich precipitates, what is the result when SPD is used to engineer nanoscale structures?
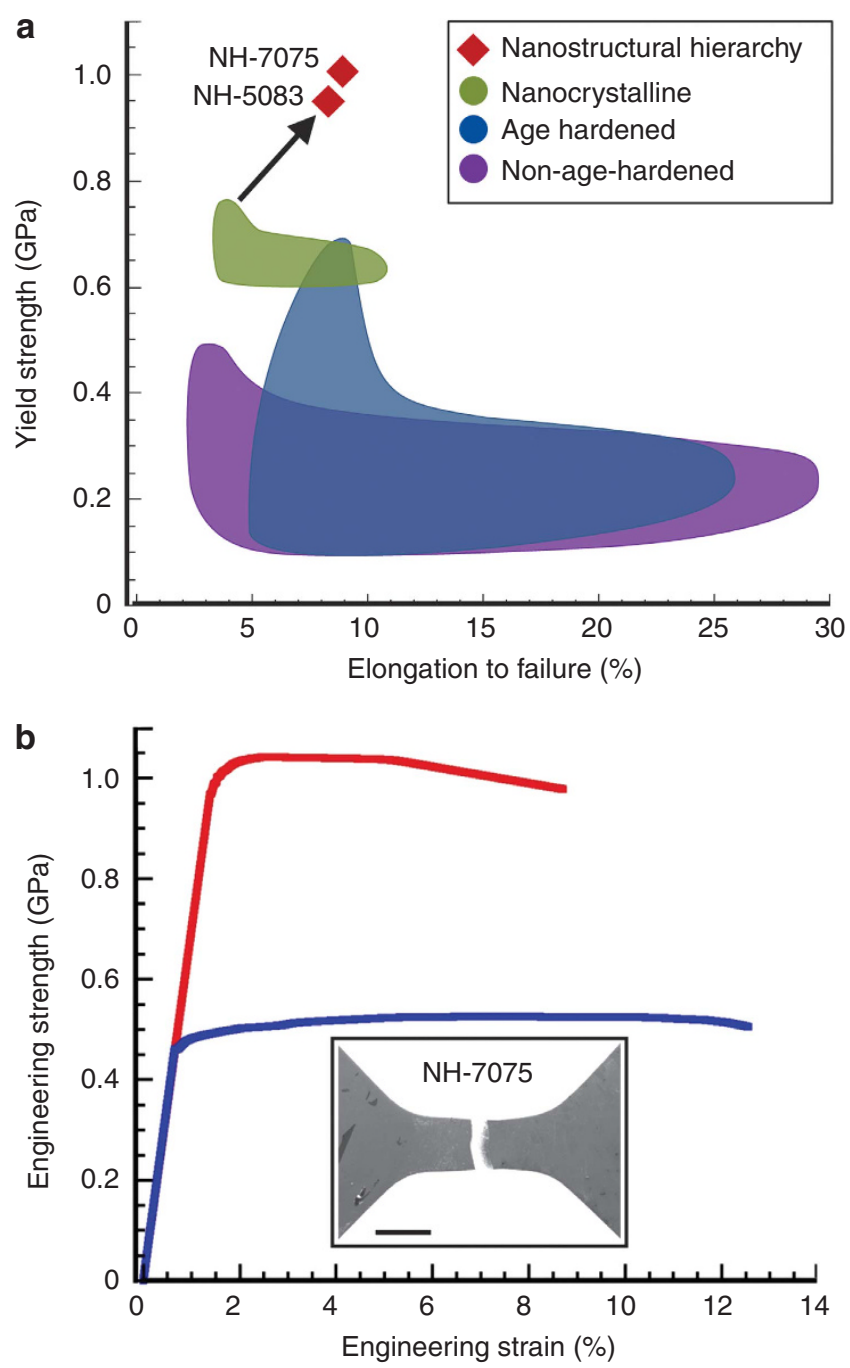

Figure 1 | Mechanical property performance of aluminium alloys. Two new aluminium alloys exhibiting record properties and solute nanostructure hierarchies (NH-7075, NH-5083). (a) A summary of the tensile properties of metallic Al alloys based on experimental data ${ }^{6-9,11-18}$. (b) A typical engineering stress-strain plot for the $\mathrm{NH}-7075$ (red curve) and T6-7075 (blue curve) alloys indicates that the HPT processing achieves nearly twice the strength of the highly used and commercially valuable T6 treated alloy. Inset is the fractured tensile specimen of the NH-7075 Al alloy; scale bar, $1 \mathrm{~mm}$. Apart from a record breaking yield strength of nearly $1 \mathrm{GPa}$, it is significant that the $\mathrm{NH}-7075$ alloy exhibits a uniform elongation of $~ 5 \%$, and total elongation-to-failure is as high as $9 \%$.

Furthermore, what relationships would such nanostructures have to the materials properties? We recently reported significant property improvement of a $5083 \mathrm{Al}$ alloy processed by highpressure torsion (HPT) (composition equivalent to Russian alloy designation 1570$)^{7}$. The alloy had an average grain size of $130 \mathrm{~nm}$ and was free of new precipitation. In this study we present a new $7075 \mathrm{Al}$ alloy that expands the known limits of mechanical property performance and provide a comprehensive atomic level investigation of the structure using new high-resolution characterization techniques for both nanostructured alloys. The aerospace-grade 7075 alloy exhibits a yield strength and uniform elongation approaching $1 \mathrm{GPa}$ and 5\%, respectively, and both alloys contain a solid solution, free of precipitation, featuring (i) a high density of dislocations, (ii) subnanometre intragranular solute clusters, (iii) two geometries of nanometre-scale intergranular solute structures and (iv) grain 
a

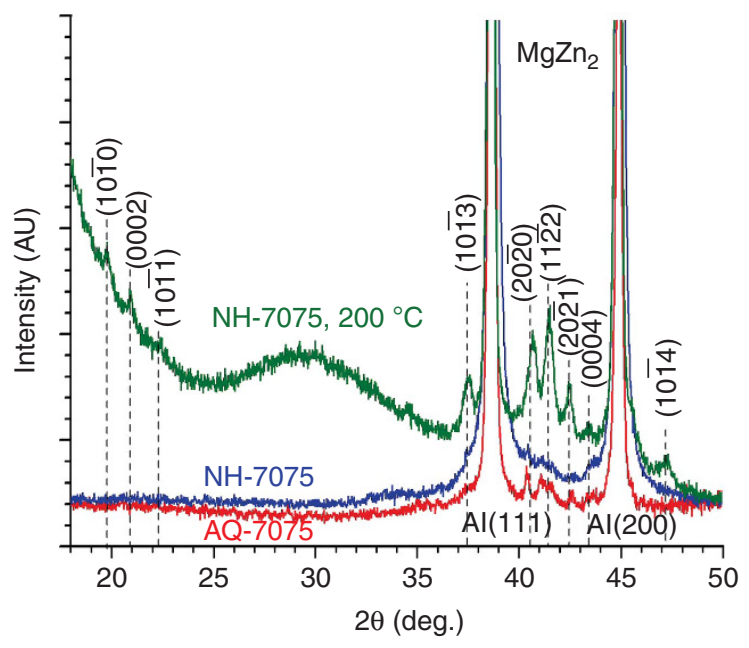

b

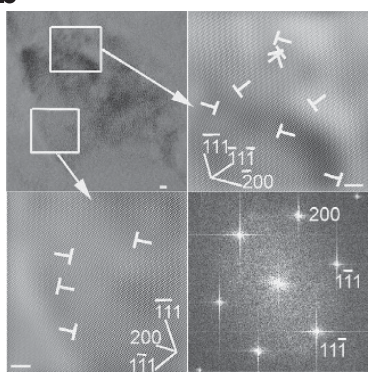

C

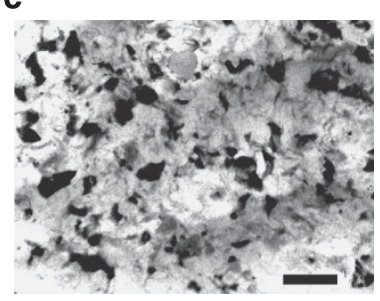

Figure 2 | X-ray and HRTEM characterization. (a) X-ray diffraction patterns of the quenched 7075 alloy before HPT processing (AQ-7075), HPT processed $7075 \mathrm{Al}(\mathrm{NH}-7075)$ and heated $\mathrm{NH}-7075$ to $200^{\circ} \mathrm{C}\left(\mathrm{NH}-7075,200^{\circ} \mathrm{C}\right)$ demonstrate that second-phase particles are not detected after $\mathrm{HPT}$ processing unless heated to $200^{\circ} \mathrm{C}$, and that the remnant hexagonal $\mathrm{MgZn}_{2}$ in the $\mathrm{AQ}$ condition is largely dissolved by the processing. The uneven XRD background (such as the broad peak) of the heated sample results from the sample holder. (b) High-resolution TEM reveals a high density of dislocations, marked by ' $T$ ' at dislocation cores in the two magnified inverse Fourier transformation images (top left and lower right panels), appearing in both grain interiors and near grain-boundary regions. The fcc solid solution is also observed to be free of precipitation, as revealed by the diffraction pattern in the lower left panel. Scale bar width is $2 \mathrm{~nm}$. (c) Bright-field image of the $\mathrm{NH}-7075$ Al alloy. Scale bar width is $100 \mathrm{~nm}$.

sizes tens of nanometres in diameter. Our results demonstrate that this novel architecture offers a design pathway towards a new generation of super-strong materials with new regimes of propertyperformance space.

\section{Results}

Materials and mechanical properties. We have prepared two types of samples of an aerospace-grade $7075 \mathrm{Al}$ alloy: one by a conventional T6 treatment and the other by HPT engineering. Our stress-strain results, presented in Figures $1 \mathrm{a}$ and b, demonstrate an average tensile yield strength and uniform elongation for the HPT alloy (NH-7075) of $0.9775 \pm 0.015 \mathrm{GPa}$ and $4.85 \pm 0.62 \%$, respectively. The plot in Figure 1a provides a general summary of the fundamental tensile properties of a wide range of metallic $\mathrm{Al}$ alloys ${ }^{6-9}$. Focussing on the $\mathrm{NH}-7075$ alloy, necking is evident when the engineering strain is $>5 \%$, and typically resulted in a total elongation to failure of $9 \%$. It is observed that the tendency for postyield strain softening is greatly inhibited in the alloy. These mechanical properties increase the present known limit for the strength of a thermomechanically processed wrought $\mathrm{Al}$ alloy prepared by ingot metallurgy and represent approximately twice the strength of a standard T6 agehardening treatment.

Alloy characterization. Conventional X-ray diffraction (XRD) analyses, presented in Figure 2a, indicate that the usual minor quantity of second-phase particles remaining after solution treatment was dissolved into the $\mathrm{Al}$ matrix by HPT processing. High-resolution TEM (HRTEM) analyses further confirmed the XRD results: the microstructure mostly appears as a continuous solid solution, as demonstrated by the HRTEM images in Figure 2b. Studying the HRTEM images reveals a high density of dislocations within grain interiors and both near and at grain boundaries; dislocation density is $\sim 3.2 \times 10^{16} \mathrm{~m}^{-2}$. The dislocations near and at the grain boundaries have previously been found to form non-equilibrium and smallangle boundaries, respectively ${ }^{27-28}$. Bright-field TEM indicates that the present nanostructured 7075 alloy has a $26 \mathrm{~nm}$ average grain diameter (Fig. 2c). The microstructural assessment exhibits similar features to the previously reported $5083 \mathrm{Al}_{\text {alloy}}$.

Novel nanoscale chemical and spatial analysis. To investigate the nanostructure and origins for these outstanding properties, we have developed a new atom probe tomography (APT) analysis approach and applied this to these two different alloy systems: Al-Zn-Mg-based 7075 alloy and Al-Mg-Sc-based 5083 alloy. In recent years, APT has been successful in making path-finding structural and chemical measurements by virtue of its atomic resolution and elemental sensitivity ${ }^{29-33}$. Advances in instrument technology, improved precision in tomographic reconstruction and the development of application-specific data-processing algorithms have thrust modern APT to the forefront of microscopy ${ }^{34-36}$. The top images in Figures $3 \mathrm{a}$ and $\mathrm{b}$ present atom maps acquired from the 7075 and 5083 alloy systems after HPT. Inspection of these data gives a qualitative indication of structure and solute aggregation within the alloy. We have developed a novel crystal interface detection method based on analyses of atomic density to reveal the intricate network of grain boundaries; these grain-boundary maps lie below atom maps in Figures 3a and b. Assessment of the 7075 grain dimensions and morphology concurs with the TEM observations (Fig. 2). These images provide clear details of discrete grain-boundary solute enrichment. Specifically, we found that solute atoms aggregate into two basic morphologies on and around select grain boundaries and junctions. We observed point-like 'nodal' and one-dimensional 'lineal' solute arrangements (Fig. 3b, left). Careful tilting assessments of this tomographic data were conducted to confirm the relative dimensionality of these nanostructural features. The nodal solute nanostructures often occur on triple or higher-order grain-boundary junctions, have a diameter of $\sim 3.7 \mathrm{~nm}$ and are observed to occur $\sim 4 \times 10^{16} \mathrm{~cm}^{-3}$. The lineal solute nanostructures extend along grainboundary vertices, have a length and diameter of $\sim 17.5 \times \sim 4.4 \mathrm{~nm}^{2}$ and occur $5 \times 10^{16} \mu^{-3}$. The lineal nanostructures were also found to occasionally intersect, as seen by the ' $\mathrm{V}$ ' shape in Figure 4. Whereas APT analyses of other materials have reported minor 
a

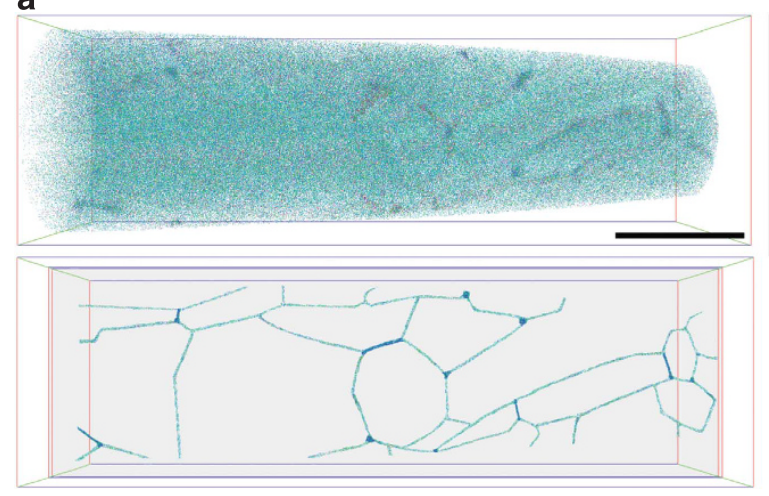

b

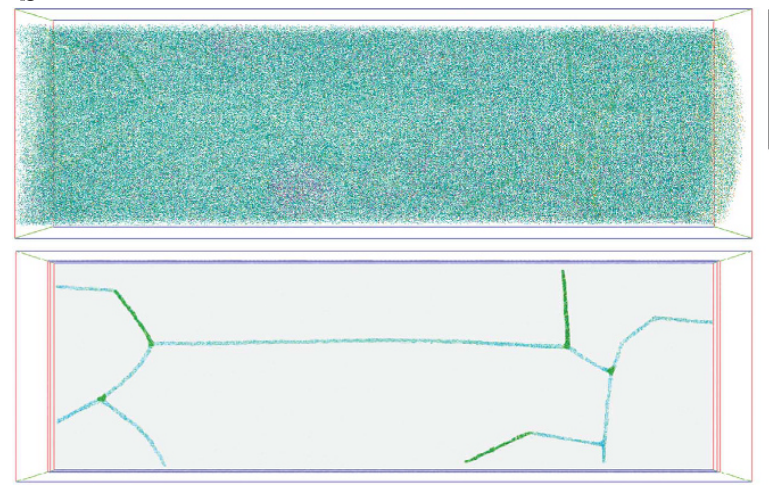

Figure 3 | Alloy grain structure. Structural and chemical insights into $\mathrm{NH}-7075$ and $\mathrm{NH}-5083$ alloys from atom probe tomography. The upper images in $(\mathbf{a}, \mathbf{b})$ are APT atom maps of specimens of the NH-7075 and $\mathrm{NH} 5083$ alloys, respectively. They reveal the first indication of structure and solute aggregation. The lower images reveal the grain-boundary locations in a thin 1-nm-thick slice of data. Solute is observed to aggregate at certain locations on the boundaries. Scale bar, $50 \mathrm{~nm}$.
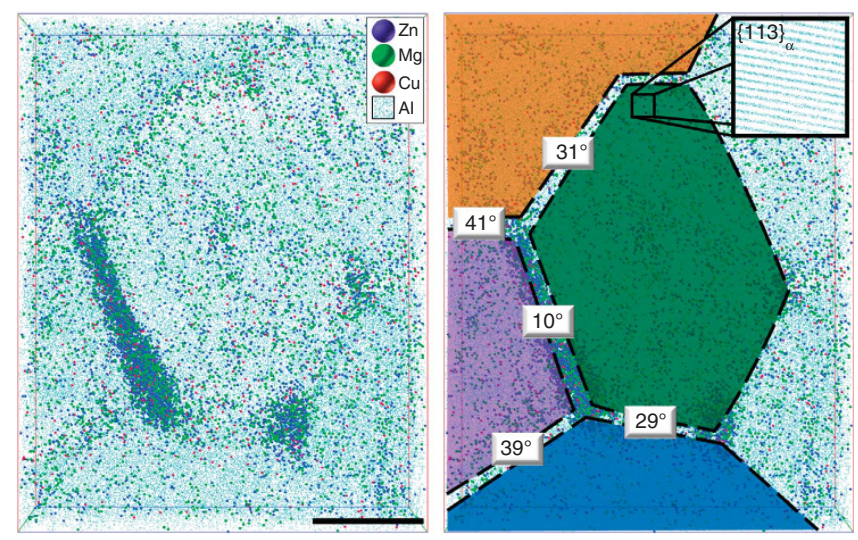

Figure 4 | Nanoscale texture measurements. Portrait of a grain in the $\mathrm{NH}-7075$ alloy; left, as an atom map, right, with a nanoscale texture map overlaid, indicating the misorientation angle between grains. The lineal solute structure is observed on a grain boundary with a crystal misorientation of $10^{\circ}$. Scale bar width is $5 \mathrm{~nm}$.

global solute segregation to grain boundaries ${ }^{9,37-38}$, the present findings are significant, as they reveal concentrated and discrete nanometre-sized solute structures at selected grain boundaries. The atom map in Figure $3 \mathrm{c}$ (left) indicates that the intragranular solute is also clustered. Core-linkage clustering algorithm was used to perform a quantitative investigation ${ }^{34}$. Our analysis of cluster number density a
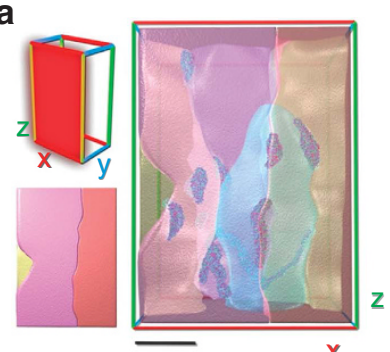

C
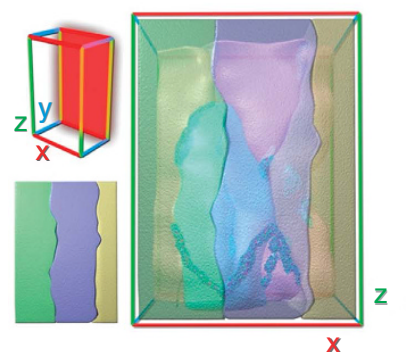

d
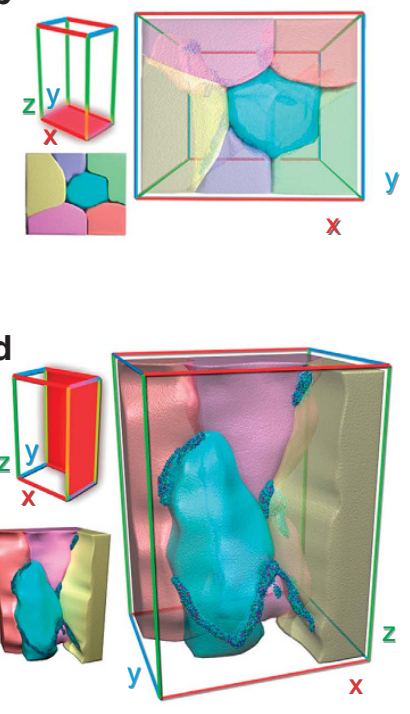

Figure 5 | Tomographic views of nanostructural architecture in NH-7075 alloy. Line- and node-shaped solute nanostructures strengthen grainboundary interfaces and junctions. This is communicated through various semitransparent orthographic projections (a-c), and one off-axis, solid, perspective view with certain grains removed to highlight the intergranular nanostructures (d). Scale bar width is $10 \mathrm{~nm}$.

is provided in Figure 5. The occurrence of randomly occurring solute clusters was assessed and subtracted from the experimentally observed number density. This analysis reveals that a high concentration of clusters of size 4-7 solute atoms have developed preferentially as the modal cluster type.

A more detailed examination of the complex three-dimensional grain-boundary network revealed information on the selective nature of the nodal and lineal solute nanostructures. The right-hand side image of Figure 4 is a nanoscale grain misorientation map derived from APT data: the first published image of this type (see Methods). An example high-resolution image of the $\{113\}_{\alpha}$ lattice planes from within the central grain is inset in Figure 4 (right) and other families of crystal planes were similarly observed in this and surrounding grains. Thus, we determined that lineal solute nanostructures were observed exclusively on relatively low-angle grain boundaries, $\leq 12^{\circ}$. Present statistics on grain misorientation at the region analysed (a half-radius distance from the specimen centre) suggest that $\leq 50 \%$ of boundaries are low angle in nature ${ }^{39}$. Within the two-dimensional grain-boundary surface, lineal structures were observed to follow along the crest of regions of higher grain-boundary curvature. The most obvious characteristic of the sites for solute nodes was that they occurred at grain-boundary junction points, such as triple points. Evidence for this analysis is provided in Figure 5, in which the nanocrystalline topography and grain-boundary solute architecture are imaged in three dimensions.

Table 1 provides a summary of the solute balance across the hierarchy of nanostructures in the 7075 alloy (NH-7075); the bulk 7075 alloy composition was determined by metallurgical analysis. At $\sim 2.5$ atom \% each, $\mathrm{Zn}$ and $\mathrm{Mg}$ are the two most prominent alloying elements in the 7075 alloy, representing a 1:1 stoichiometric ratio. Combining the information on chemistry and number density, we obtain the relative balance of solute across the observed hierarchy of nanostructural architecture: we find that $38.49 \%$ of the solute in the alloy is involved in atomic clustering and most of this is allocated to modal clusters of size $4-7$ atoms, with another $51.35 \%, 8.33 \%$ and $1.87 \%$ of the solute allocated in the matrix, lines and nodes, respectively. 


\begin{tabular}{|c|c|c|c|c|}
\hline Atom \% & NH-7075 alloy & Cluster & Line & Node \\
\hline $\mathrm{Al}$ & 93.6 & 35.98 & 55.40 & 58.00 \\
\hline $\mathrm{Zn}$ & 2.55 & 28.56 & 25.44 & 23.78 \\
\hline $\mathrm{Mg}$ & 2.89 & 28.85 & 15.96 & 15.34 \\
\hline $\mathrm{Cu}$ & 0.61 & 5.75 & 2.20 & 2.01 \\
\hline $\mathrm{Si}$ & 0.11 & 0.48 & 0.14 & 0.18 \\
\hline $\mathrm{Cr}$ & 0.10 & 0.26 & 0.24 & 0.21 \\
\hline $\mathrm{Ti}$ & 0.01 & 0.13 & 0.61 & 0.48 \\
\hline \multicolumn{5}{|c|}{$\begin{array}{l}\text { Atomic composition of the } \mathrm{NH}-7075 \text { alloy and solute structures. The standard deviation for } \\
\text { element values are }<8 \% \text {. A } 1: 1 \text { ratio of } \mathrm{Zn:Mg} \text { (similar to the matrix) exists in the solute } \\
\text { clusters, but at } 12 \text { times the nominal concentration level. A ratio of } 1.5: 1, \mathrm{Zn}: \mathrm{Mg} \text {, evolves in } \\
\text { the line and node nanostructures, which is similar to traditional measurements of the solute } \\
\text { ratio in the metastable } \eta^{\prime} \text { precipitates that strengthen } 7000 \text { series alloys }{ }^{40} \text {. }\end{array}$} \\
\hline
\end{tabular}

The 1:1 stoichiometric ratio for $\mathrm{Zn}$ and $\mathrm{Mg}$ is reflected in the cluster chemistry, but at $\sim 12$ times higher concentrations than in the bulk alloy. In addition to containing the highest levels of $\mathrm{Cu}$ atoms, these clusters have the greatest concentration of solute of the three nanostructures at $\sim 64$ atom \%. The nodal and lineal structures exhibit $\mathrm{Zn}: \mathrm{Mg}$ ratios of approximately $1.5: 1$, which is similar to compositions traditionally measured for the solute ratio of the metastable $\eta^{\prime}$ precipitates that are widely cited as the main strengthening element in 7000-series alloys ${ }^{6,40}$. The lineal structures are $\sim 5.5$ atom $\%$ richer in total solute than the nodes, and both the lines and nodes contain elevated levels of Ti. Combining the information on chemistry and number density, we find that $38.49 \%$ of the solute in the alloy is involved in atomic clustering and most of this is allocated to the modal clusters of size 4-7 atoms. This compares with only $1.87 \%$ of solute in nodes, and with $8.33 \%$ in the lineal nanostructures. The remainder $(\sim 51 \%)$ of the total solute atoms exists in the solid solution in a non-clustered state.

\section{Discussion}

We have engineered two crystalline $\mathrm{Al}$ alloys to increase the present limits of strength. These alloys feature a nanostructural hierarchy of (i) high dislocation density, (ii) subnanometre intragranular solute clusters, (iii) two geometries of nanometre-scale intergranular nanostructures and (iv) grain sizes tens of nanometres in diameter. In the literature, strength $>1 \mathrm{GPa}$ is reached only for $\mathrm{Al}$ metallic glasses and for composite $\mathrm{Al}$ alloys strengthened by ceramic particles ${ }^{41-43}$. This solute architecture is non-intuitive and, to our knowledge, has not previously been reported. These solute-rich nanostructures are all an intrinsic part of the $\alpha$-fcc lattice, and none represent a distinct second-phase in the way that, for example, precipitate particles do. We propose that this architecture primarily occurs because of solute-defect (dislocation, point defects and so on) interactions during the nanostructuring process. The high concentration of mobile defects during processing greatly influences the solute dispersion, and the resulting hierarchy reflects an energy landscape in which intragranular solute-clustering and intergranular solute-structuring reactions provide local reductions in free energy. The solute atoms swept to grain boundaries diffuse and populate lineally along grain boundaries and aggregate nodally at grain-boundary junctions. These observations present a fresh perspective to further pursue the origins of material properties and a new starting point for the modelling of strengthening effects.

Although it might be considered that the nanocrystalline grain size alone could account for the alloy strength through restriction of dislocation generation and mobility, as described by the Hall-Petch relation, we find, for example, that the parametric constants for the Hall-Petch equation previously determined for pure Al predict a strength of only $\sim 0.27 \mathrm{GPa}$ for the $26 \mathrm{~nm}$ average grain size ${ }^{44}$. Similarly,

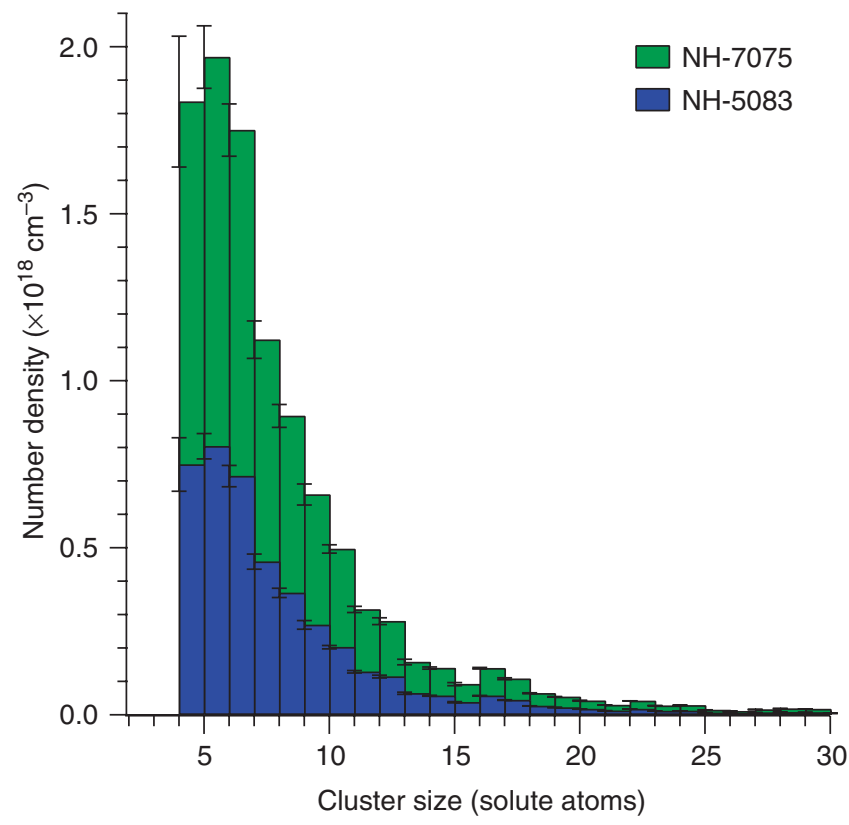

Figure 6 | Number density of intragranular solute cluster Al alloys. This is shown in green for $\mathrm{NH}-7075$ and in blue for $\mathrm{NH}-5083$. A high concentration of clusters sized 5-9 solute atoms are observed to occur preferentially. The experimentally observed frequency of solute clusters has had the expected random occurrences subtracted (see Methods); error bars are standard deviation.

the dissolved (non-clustered) solute will provide very limited conventional solid-solution hardening, considering that a solutiontreated $7075 \mathrm{Al}$ alloy with $100 \%$ of the solute in the matrix has a strength of $0.145 \mathrm{GPa}$, whereas only about half $(\sim 51 \%$, Fig. 6$)$ of the solute remains dissolved in the current sample ${ }^{8}$. Thus, we propose that the near $1 \mathrm{GPa}$ strength and $9 \%$ elongation arise from combining the grain size with the observed nanostructural architecture. With regard to the five main deformation mechanisms that might be expected-preexisting dislocation gliding, grain-boundary dislocation emission, grain-boundary sliding, grain rotation and grainboundary migration-strengthening is expected to occur through the following ${ }^{24,26,43,45-47}$. First, the high density of intragranular solute clusters (comprising $\sim 38 \%$ of the total solute) can contribute to significant cluster strengthening, thereby providing effective resistance to slip dislocations, as well as to strain hardening and ductility, by increasing the dislocation storage capability ${ }^{8,48}$. Solute clustering has long been reported in conventional coarse-grained or microcrystalline, wrought $7000 \mathrm{Al}$ alloys and linked to strengthening ${ }^{48-52}$. For example, alloy hardness can nearly double in the first minute of T6 ageing in a process that cannot be attributed to precipitation $^{53,54}$. Furthermore, the dislocations observed within grains may be stabilized by forming Cottrell atmosphere-like solute clustering at the dislocation cores. The strong association of solute to defects in alloys similar to the 7075 composition is well established through positron spectroscopy techniques, and a critical defect concentration has long been established as being essential to the heterogeneous nucleation of metastable precipitates ${ }^{49-52,55}$. The other major architectural features of this solid solution are the intergranular solute nanostructures at grain boundaries. These are expected to providesegregation-basednanocrystalgrowthstabilization, strengthening interface bond cohesion, and resisting embrittlement and defect generation ${ }^{23,56}$. These nodal and lineal solute nanostructures will similarly retard dislocations nucleated at the grain boundaries. Any grain-boundary sliding and rotation will require the breaking or plastic deformation of the intergranular nanostructures, making 
these energetically more expensive and restricted processes as well. The lineal solute nanostructures on grain boundaries, as observed here, will be available to immobilize grain-boundary dislocations produced during the HPT, and will further strengthen the 7075 alloy. Such dislocations usually exist on non-equilibrium grain boundaries in nanocrystalline metals processed by SPD and are believed to have a significant role in the deformation of nanocrystalline metals ${ }^{27,46}$. Room temperature grain-boundary migration under stress has most recently been reported in pure $\mathrm{Al}$ with grains of similar size ${ }^{45}$. It is likely that any diffusion-induced migration will be stabilized by the grain-boundary enrichment and that any athermal shear (dislocation-based processes) that would produce the glide of low-angle grain boundaries would encounter similar resistance to that discussed above.

This nanostructural analysis allows us to contemplate the development of a nanostructural texture, in which information on grain misorientations is combined precisely with information on the solute architecture. The atom probe techniques developed here (for example, Fig. 4) will be useful in future development of this concept. The present observations suggest that the hierarchy and architecture of solute have an important influence on nanocrystallinity, grain texture and alloy strengthening. Control of this solute architecture holds promise for development of a new generation of advanced alloys with new regimes of property-performance space.

\section{Methods}

Specimen preparation. Commercial 7075 and $5083 \mathrm{Al}$ alloy rods with atomic composition Al-2.55Zn-2.89Mg-0.61Cu-0.11Si-0.10Cr-0.01Ti and Al-6.3Mg$0.1 \mathrm{Sc}-0.1 \mathrm{Mn}$ were solution treated at $480^{\circ} \mathrm{C}$ for $5 \mathrm{~h}$ and at $380^{\circ} \mathrm{C}$ for $2 \mathrm{~h}$, respectively, and then quenched into room-temperature water. The solution-treated rod was machined into $20 \mathrm{~mm}$ diameter by $0.8-\mathrm{mm}$-thick discs. The discs were processed by HPT for 10 revolutions for 7075 and for 20 revolutions for 5083, under a pressure of $6 \mathrm{GPa}$ at room temperature; time elapsed between quench and HPT processing was $<20 \mathrm{~min}$.

Mechanical property testing. Tensile tests were conducted at room temperature at a strain rate of $10^{-4} \mathrm{~s}^{-1}$. The tests were computer controlled, registering temperature, strain and stress. Sample dimensions were accurately measured in our experiments. A laser extensometer, P-50 by Fiedler Optoelectronics, was used to accurately measure the strain. ${ }^{9}$ Tensile specimens had $1 \mathrm{~mm}$ width and $0.5 \mathrm{~mm}$ thickness with a 2 -mm-gauge length. The load cell was well calibrated and measurements were determined with a Hottinger Baldwin Messtechnik GmbH firm load sensor with 0.5 tolerance class. Tensile and microscopy specimens were taken from the area at a half-radius distance from the centre of processed discs. Four selfconsistent uniaxial tensile tests were completed. The use of miniature specimens has been previously investigated in detail; our studies indicate that, although the strain measurement method and tensile specimen geometry can affect the results, when the strain is accurately measured, the specimen size and geometry only affect the postnecking elongation ${ }^{57,58}$.

Characterization techniques. XRD measurements were taken on a Scintag X-ray diffractometer (Scintag) equipped with a Cu target operating at $1.8 \mathrm{~kW}$. $\theta-2 \theta$ step scans were taken to record the XRD patterns at room temperature. The scanning step is $0.02^{\circ}$ and the scanning rate is $10 \mathrm{~s}$ per step. The XRD scanning areas of $\mathrm{NH}-7075 \mathrm{Al}$ and AQ-7075 $\mathrm{Al}$ are dick shaped with a diameter of $20 \mathrm{~mm}$ and are therefore comparative. For the NH-7075 at $200^{\circ} \mathrm{C}$, a $4 \times 4 \mathrm{~mm}^{2}$ sheet of NH-7075 $\mathrm{Al}$ was heated to $200^{\circ} \mathrm{C}$ in argon atmosphere by differential scanning calorimeter at a heating rate of $5^{\circ} \mathrm{C}$ per min, and used for XRD scanning. The XRD patterns of NH-7075 and NH-7075 were recorded at $200^{\circ} \mathrm{C}$ upwards in order to see signals of precipitates clearly. The uneven XRD background (such as the broad peak) of the heated sample results from the sample holder. TEM and APT specimens were prepared by standard electropolishing techniques ${ }^{59,60}$. Low-energy ion milling was used to clean the TEM foils. TEM was performed on a Philips CM12 (Philips) and a JEOL JEM3000F (JEOL). APT was performed on an Imago LEAP 3000Xsi (Imago). APT acquisitions were performed at a temperature of $20 \mathrm{~K}$, a pulse frequency of $200 \mathrm{kHz}$, a $25 \%$ pulse fraction and a $1 \%$ evaporation rate. The reconstruction of APT data was carefully calibrated to crystallographic parameters. Before analysis, low-density erosion of zone and pole lines in the APT data was performed $^{34}$; a 100 nearest-neighbour $(\mathrm{NN})$ analysis with a 22.5 atoms per $\mathrm{nm}^{3}$ low-density threshold and $0.5 \mathrm{~nm}$ erosion distance was used. Data analysis was performed by using the core-linkage clustering algorithm using atomic point densities $^{36}$. A $26 \mathrm{NN}$ density analysis was used for grain-boundary identification. A $1 \mathrm{NN}, 2.5$ atoms per $\mathrm{nm}^{3}$ point density and 0.4-nm d-link core-linkage analysis were used to assess atomic clustering. Taking an atom probe data set and randomly reassigning each atom's element type, according to nominal composition, an identical but chemically homogenous data set could be generated ${ }^{30}$; the average cluster-size frequencies and standard deviations of 15 homogenized data sets were subtracted from the experimentally observed frequencies to produce Figure 4 . The misorientation of the $\{001\}_{\alpha}$ plane in each crystal was used to assess texture. When the $\{001\}_{\alpha}$ was not available, the linear algebraic relationships between a minimum of three non-orthogonal atomic planes were measured and numerically solved for the $\{001\}_{\alpha}$ plane, with a sum of squares difference error of $<1.0^{\circ}$.

\section{References}

1. Wassermann, G. \& Weerts, J. On the mechanism of $\mathrm{CuAl}_{2}$-precipitation in an age-hardenable aluminium alloy. Metallwirtsch. 14, 605 (1935).

2. Guinier, A. Structure of age-hardened aluminium-copper alloys. Nature 142, 569 (1938)

3. Preston, G. D. Structure of age-hardened aluminium-copper alloys. Nature 142, 570 (1938).

4. Polmear, I. J. \& Hardy, H. K. Some metallographic observations on aged aluminium-copper alloys. J. Inst. Met. 81, 427-432 (1952-53).

5. Silcock, J. M., Heal, T. J. \& Hardy, H. K. Some metallographic observations on aged aluminium-copper alloys. J. Inst. Met. 82, 239-248 (1953-54).

6. Polmear, I. J. Light Alloys, From Traditional Alloys to Nanocrystals 4th edn, (Elsevier, 2006).

7. Murashkin, M., Kil'mametov, A. R. \& Valiev, R. Z. Structure and mechanical properties of an aluminum alloy 1570 subjected to severe plastic deformation by high-pressure torsion. Phys. Met. Metallogr. 106, 90-96 (2008).

8. Zhao, Y. H., Liao, X. Z., Cheng, S., Ma, E. \& Zhu, Y. T. Simultaneously increasing the ductility and strength of nanostructured alloys. Adv. Mater. 18, 2280-2283 (2006).

9. Nurislamova, G., Sauvage, X., Murashkin, M., Islamgaliev, R. K. \& Valiev, R. Z. Nanostructure and related mechanical properties of an Al-Mg-Si alloy processed by severe plastic deformation. Philos. Mag. Lett. 88, 459-466 (2008).

10. Valiev, R. Z., Krasilnikov, N. A. \& Tsenev, N. K. Plastic deformation of alloys with submicro-grained structure. Mater. Sci. Eng. A 137, 35-40 (1991).

11. Valiev, R. Z., Islamgaliev, R. K. \& Alexandrov, I. V. Bulk nanostructured materials from severe plastic deformation. Prog. Mater. Sci. 45, 103-189 (2000).

12. Wang, Y., Chen, M., Zhou, F. \& Ma, E. High tensile ductility in a nanostructured metal. Nature 419, 912-915 (2002).

13. Zhao, Y. H., Liao, X. Z., Jin, Z., Valiev, R. Z. \& Zhu, Y. T. Microstructures and mechanical properties of ultrafine grained $7075 \mathrm{Al}$ alloy processed by ECAP and their evolutions during annealing. Acta Mater. 52, 4589-4599 (2004)

14. Valiev, R. Z. Nanostructuring of metals by severe plastic deformation for advanced properties. Nat. Mater. 3, 511-516 (2004).

15. Wang, Y. M. \& Ma, E. Three strategies to achieve uniform tensile deformation in a nanostructured metal. Acta Mater. 52, 1699-1709 (2004).

16. Valiev, R. Z. \& Langdon, T. G. Principles of equal-channel angular pressing as a processing tool for grain refinement. Prog. Mater. Sci. 51, 881-981 (2006).

17. Choi, H. J., Lee, S. W., Park, J. S. \& Bae, D. H. Tensile behavior of bulk nanocrystalline aluminum synthesized by hot extrusion of ball-milled powders Scr. Mater. 59, 1123-1126 (2008).

18. Zhilyaev, A. P. \& Langdon, T. G. Using high-pressure torsion for metal processing: fundamentals and applications. Prog. Mater. Sci. 53, 893-979 (2008).

19. Zhilyaev, A. P. et al. Experimental parameters influencing grain refinement and microstructural evolution during high-pressure torsion. Acta Mater. 51, 753-765 (2003).

20. Stolyarov, V. V., Zhu, Y. T., Alexandrov, I. V., Lowe, T. C. \& Valiev, R. Z. Influence of ECAP routes on the microstructure and properties of pure Ti. Mater. Sci. Eng. A 299, 59-67 (2001).

21. Chokshi, A. H., Rosen, A., Karch, J. \& Gleiter, H. On the validity of the hall-petch relationship in nanocrystalline materials. Scr. Metall. Mater. 23, 1679-1683 (1989).

22. Meyers, M. A., Mishra, A. \& Benson, D. J. Mechanical properties of nanocrystalline materials. Prog. Mater. Sci. 51, 427-556 (2006).

23. Shen, T. D. et al. Effect of solute segregation on the strength of nanocrystalline alloys: inverse Hall-Petch relation. Acta Mater. 55, 5007-5013 (2007).

24. Yamakov, V., Wolf, D., Phillpot, S. R., Mukherjee, A. K. \& Gleiter, H. Dislocation processes in the deformation of nanocrystalline aluminium by molecular-dynamics simulation. Nat Mater. 1, 45-49 (2002).

25. Schiøtz, J. \& Jacobsen, K. W. A maximum in the strength of nanocrystalline copper. Science 301, 1357-1359 (2003).

26. Van Swygenhoven, H., Derlet, P. M. \& Froseth, A. G. Stacking fault energies and slip in nanocrystalline metals. Nat. Mater. 3, 399-403 (2004).

27. Huang, J. Y., Zhu, Y. T., Jiang, H. \& Lowe, T. C. Microstructures and dislocation configurations in nanostructured $\mathrm{Cu}$ processed by repetitive corrugation and straightening. Acta Mater. 49, 1497-1505 (2001).

28. Liao, X. Z., Huang, J. Y., Zhu, Y. T., Zhou, F. \& Lavernia, E. J. Nanostructures and deformation mechanisms in a cryogenically ball-milled Al-Mg alloy. Philos. Mag. 83, 3065-3075 (2003). 
29. Gault, B. et al. in Frontiers in Materials Research (eds Fujikawa, Y., Nakajima, K., \& Sakurai, T.) 187-216 (Springer, 2008)

30. Allen, J. E. et al. High-resolution detection of Au catalyst atoms in Si nanowires. Nat. Nano. 3, 168-173 (2008).

31. Thompson, K., Flaitz, P. L., Ronsheim, P., Larson, D. J. \& Kelly, T. F. Imaging of arsenic cottrell atmospheres around silicon defects by three-dimensional atom probe tomography. Science 317, 1370-1374 (2007).

32. Mao, Z., Sudbrack, C. K., Yoon, K. E., Martin, G. \& Seidman, D. N. The mechanism of morphogenesis in a phase-separating concentrated multicomponent alloy. Nat. Mater. 6, 210-216 (2007).

33. Perea, D. E. et al. Direct measurement of dopant distribution in an individual vapour-liquid-solid nanowire. Nat. Nano. 4, 315-319 (2009).

34. Stephenson, L. T., Moody, M. P., Liddicoat, P. V. \& Ringer, S. P. New techniques for the analysis of fine-scaled clustering phenomena within atom probe tomography (APT) data. Microsc. Microanal. 13, 448-463 (2007).

35. Moody, M. P., Stephenson, L. T., Liddicoat, P. V. \& Ringer, S. P. Contingency table techniques for three dimensional atom probe tomography. Microsc. Res. Tech. 70, 258-268 (2007).

36. Gault, B. et al. Estimation of the reconstruction parameters for atom probe tomography. Microsc. Microanal. 14, 296-305 (2008).

37. Detor, A. J., Miller, M. K. \& Schuh, C. A. Solute distribution in nanocrystalline $\mathrm{NiW}$ alloys examined through atom probe tomography. Philos. Mag. 86, 4459-4475 (2006).

38. Hentschel, T., Isheim, D., Kirchheim, R., Müller, F. \& Kreye, H. Nanocrystalline Ni-3.6 at.\% $\mathrm{P}$ and its transformation sequence studied by atom-probe field-ion microscopy. Acta Mater. 48, 933-941 (2000).

39. Orlov, D., Todaka, Y., Umemoto, M. \& Tsuji, N. Role of strain reversal in grain refinement by severe plastic deformation. Mater. Sci. Eng. A 499, 427-433 (2009).

40. Maloney, S. K., Hono, K., Polmear, I. J. \& Ringer, S. P. The chemistry of precipitates in an aged Al-2.1Zn-1.7Mg at.\% alloy. Scr. Mater. 41, 1031-1038 (1999).

41. Choi, G. S., Kim, Y. H., Cho, H. K., Inoue, A. \& Masumoto, T. Ultrahigh tensile strength of amorphous Al-Ni-(Nd,Gd)-Fe alloys containing nanocrystalline Al particles. Scr. Metall. Mater. 33, 1301-1306 (1995).

42. Mu, J. et al. Synthesis and properties of Al-Ni-La bulk metallic glass. Adv. Eng Mater. 11, 530-532 (2009).

43. Shan, Z. et al. Grain boundary-mediated plasticity in nanocrystalline nickel. Science 305, 654-657 (2004).

44. Hansen, N. Hall-Petch relation and boundary strengthening. Scr. Mater. 51, 801-806 (2004)

45. Legros, M., Gianola, D. S. \& Hemker, K. J. In situ TEM observations of fast grain-boundary motion in stressed nanocrystalline aluminum films. Acta Mater. 56, 3380-3393 (2008).

46. Zhu, Y. T., Liao, X. Z., Srinivasan, S. G. \& Lavernia, E. J. Nucleation of deformation twins in nanocrystalline face-centered-cubic metals processed by severe plastic deformation. J. Appl. Phys. 98, 034319 (2005).

47. Chinh, N. Q., Szommer, P., Horita, Z. \& Langdon, T. G. Experimental evidence for grain-boundary sliding in ultrafine-grained aluminum processed by severe plastic deformation. Adv. Mater. 18, 34-39 (2006)

48. Ringer, S. P. \& Hono, K. Microstructural evolution and age hardening in aluminium alloys: atom probe field-ion microscopy and transmission electron microscopy studies. Mater. Charact. 44, 101-131 (2000)

49. Ryum, N. Precipitation kinetics in an Al-Zn-Mg-alloy. Z. Metallk. 66, 338 (1975)
50. Katz, Z. \& Ryum, N. Precipitation kinetics in Al-alloys. Scr. Metall. Mater. 15 265-268 (1981)

51. Juhász, A., Kovács, I., Lendvai, J. \& Tasnádi, P. Initial clustering after quenching in AlZnMg alloys. J. Mater. Sci. 20, 624-629 (1985).

52. Liddicoat, P. V., Ferragut, R., Dupasquier, A. \& Ringer, S. P. Analysis of Vacancy Complexes in Al-Zn-Mg(-Cu) Alloys During Early Stages of Age Hardening Vol. 1, 808-814 (Wiley-VCH Verlag GmbH \& Co. KGaA, 2008).

53. Polmear, I. J. The ageing characteristics of complex Al-Zn-Mg alloys. J. Inst. Met. 89, 51-59 (1960).

54. Liddicoat, P. V., Honma, T., Stephenson, L. T. \& Ringer, S. P. Evolution of nanostructure during the early stages of ageing in $\mathrm{Al}-\mathrm{Zn}-\mathrm{Mg}-\mathrm{Cu}$ alloys. Mater. Sci. For. 519-521, 555-560 (2006).

55. Deschamps, A., Brechet, Y., Guyot, P. \& Livet, F. On the influence of dislocations on precipitation in an Al-Zn-Mg alloy. Metallkd 88, 601-606 (1997).

56. Detor, A. J. \& Schuh, C. A. Grain boundary segregation, chemical ordering and stability of nanocrystalline alloys: Atomistic computer simulations in the Ni-W system. Acta Mater. 55, 4221-4232 (2007).

57. Zhao, Y. H. et al. Influence of specimen dimensions on the tensile behavior of ultrafine-grained Cu. Scr. Mater. 59, 627-630 (2008).

58. Zhao, Y. H. et al. Influence of specimen dimensions and strain measurement methods on tensile stress-strain curves. Mater. Sci. Eng. A 525, 68-77 (2009).

59. Hirsch, P. B., Howie, A., Nicholson, R. B., Pashley, D. W. \& Whelan, M. J. Electron Microscopy of Thin Crystals (Krieger, 1977).

60. Miller, M. K. Atom Probe Tomography: Analysis at the Atomic Level (Springer, 2000).

\section{Acknowledgments}

We are grateful for scientific, technical and financial support from the Australian Microscopy \& Microanalysis Research Facility (AMMRF) node at The University of Sydney, in particular to Mr Daniel Haley and Dr Kyle Ratinac. X.Z. Liao thanks the Australian Research Council for financial support (project ID: DP0772880). Y.T. Zhu and R.Z. Valiev were supported by the DOE IPP program. Y.H. Zhao and E.J. Lavernia acknowledge support by the Office of Naval Research (N00014-08-1-0405) with Dr Lawrence Kabacoff as programme officer.

\section{Author contributions}

P.V.L. prepared, acquired and analysed APT data; X.Z.L. prepared, acquired and analysed TEM images; Y.H.Z. and E.J.L. prepared 7075 materials, acquired metallurgical composition and X-ray diffraction analyses; M.Y.M. and R.Z.V. performed the HPT and acquired mechanical tests. P.V.L., X.Z.L., Yonghao Zhou, Yuntian Zhu, E.J.L., R.Z.V. and S.P.R. designed the study. P.V.L. and S.P.R. wrote the paper. All authors discussed the results and contributed to the paper.

\section{Additional information}

Competing financial interests: The authors declare no competing financial interests.

Reprints and permission information is available online at http://npg.nature.com/ reprintsandpermissions/

How to cite this article: Liddicoat, P.V. et al. Nanostructural hierarchy increases the strength of aluminium alloys. Nat. Commun. 1:63 doi: 10.1038/ncomms1062 (2010). 